\section{(Q) \\ CrossMark}

\title{
Meta-analysis on short-term exposure to ambient ultrafine particles and respiratory morbidity
}

\author{
Evangelia Samoli ${ }^{1}$, Sophia Rodopoulou ${ }^{1}$, Alexandra Schneider ${ }^{2}$, Lidia Morawska ${ }^{3}$, \\ Massimo Stafoggia ${ }^{4}$, Matteo Renzi ${ }^{4}$, Susanne Breitner ${ }^{2,5}$, Timo Lanki ${ }^{6,7,8}$, Regina Pickford ${ }^{2}$, \\ Tamara Schikowski ${ }^{9}$, Enembe Okokon $\mathbb{1}^{6}$, Siqi Zhang ${ }^{2}$, Qi Zhao ${ }^{9}$ and Annette Peters ${ }^{2,5}$
}

Affiliations: ${ }^{1}$ Dept of Hygiene, Epidemiology and Medical Statistics, Medical school, National and Kapodistrian University of Athens, Athens, Greece. ${ }^{2}$ Institute of Epidemiology, Helmholtz Zentrum München - German Research Center for Environmental Health, Neuherberg. Germany. ${ }^{3}$ International Laboratory for Air Quality and Health, Queensland University of Technology, Brisbane, Australia. ${ }^{4}$ Dept of Epidemiology, Lazio Regional Health Service, Rome, Italy. ${ }^{5}$ IBE-Chair of Epidemiology, Ludwig Maximilians Universität München, Munich, Germany. ${ }^{6}$ Finnish Institute for Health and Welfare, Kuopio, Finland. ${ }^{7}$ University of Eastern Finland, Dept of Environmental and Biological Sciences, Kuopio, Finland. ${ }^{8}$ University of Eastern Finland, School of Medicine, Kuopio, Finland. 'Leibniz Research Institute for Environmental Medicine, Düsseldorf, Germany.

Correspondence: Evangelia Samoli, Dept of Hygiene, Epidemiology and Medical Statistics, National and Kapodistrian University of Athens Medical School, 75 MikrasAsias Street, 11527 Athens, Greece. E-mail: esamoliamed.uoa.gr

@ERSpublications

Studies on short-term exposure to ultrafine particles and respiratory admissions show large variability in the exposure assessment methodology. We found indications of effects in lower concentrations, children and during the warm period of the year. https://bit.ly/2zynMza

Cite this article as: Samoli E, Rodopoulou S, Schneider A, et al. Meta-analysis on short-term exposure to ambient ultrafine particles and respiratory morbidity. Eur Respir Rev 2020; 29: 200116 [https://doi.org/ 10.1183/16000617.0116-2020].

\section{ABSTRACT}

Aim: There is growing interest in the health effects following exposure to ambient particles with a diameter $<100 \mathrm{~nm}$ defined as ultrafine particles (UFPs), although studies so far have reported inconsistent results. We have undertaken a systematic review and meta-analysis for respiratory hospital admissions and emergency room visits following short-term exposure to UFPs.

Methods: We searched PubMed and the Web of Science for studies published up to March 2019 to update previous reviews. We applied fixed- and random-effects models, assessed heterogeneity between cities and explored possible effect modifiers.

Results: We identified nine publications, reporting effects from 15 cities, 11 of which were European. There was great variability in exposure assessment, outcome measures and the exposure lags considered. Our meta-analyses did not support UFP effects on respiratory morbidity across all ages. We found consistent statistically significant associations following lag 2 exposure during the warm period and in cities with mean daily UFP concentrations $<6000$ particles $\cdot \mathrm{cm}^{-3}$, which was approximately the median of the city-specific mean levels. Among children aged 0-14 years, a 10000 particle $\cdot \mathrm{cm}^{-3}$ increase in UFPs 2 or 3 days before was associated with a relative risk of 1.01 (95\% CI 1.00-1.02) in respiratory hospital admissions.

Conclusions: Our study indicates UFP effects on respiratory health among children, and during the warm season across all ages at longer lags. The limited evidence and the large heterogeneity of previous reports call for future exposure assessment harmonisation and expanded research.

\section{Provenance: Submitted article, peer reviewed}

This article has supplementary material available from err.ersjournals.com

Received: 23 April 2020 | Accepted: 22 May 2020

Copyright $\odot$ ERS 2020. This article is open access and distributed under the terms of the Creative Commons Attribution Non-Commercial Licence 4.0. 


\section{Introduction}

Ambient particulate matter (PM) exposure has been associated with a variety of health outcomes and the evidence is continuously growing $[1,2]$. Health impacts of particles partly vary by their size, because their size determines where particles are deposited in the airways. The majority of published research has focused on the mass concentration of particles with an aerodynamic diameter $<2.5 \mu \mathrm{m}\left(\mathrm{PM}_{2.5}\right)$, while in the last decade there has been growing research interest in smaller particles defined as ultrafine particles (UFPs) with a diameter $<100 \mathrm{~nm}$. Although there is no lower limit in this definition (if anything this would be the size of individual molecules), this is restricted by the capabilities of the monitoring techniques, with the existing instruments already measuring down to $2 \mathrm{~nm}$.

Smaller particles travel deeper into the lungs and particles $<200 \mathrm{~nm}$ can penetrate cells and reach multiple organs [3]. Biological mechanisms have been proposed regarding UFP toxicity that seems to differ from larger particles [4]. This is attributed to differences in the deposition upon inhalation, and in differential physicochemical properties [5]. Oxidative stress is a common mechanism of response that leads to inflammation and tissue damage. Li et al. [6] showed that differences in the size and composition of coarse $(2.5-10 \mu \mathrm{m})$, fine $(<2.5 \mu \mathrm{m})$ and ultrafine $(<0.1 \mu \mathrm{m})$ PMs are related to their uptake in macrophages and epithelial cells and their ability to induce oxidative stress.

In 2013, the US Health Effects Institute [7] published a report on UFP health effects that concluded that there was insufficient evidence of adverse effects. However, a study that reviewed the literature up to 2017 [8] indicated associations with inflammatory and cardiovascular changes following short-term exposure to UFPs, which may be partly independent of other pollutants, and in particular of $\mathrm{PM}_{2.5}$. The authors reported six studies investigating adult or paediatric asthma-related visits or admissions and concluded that the association seemed most probable for children. Recently the US Environmental Protection Agency Integrated Science Assessment for PM [9] concluded that there is suggestive evidence of respiratory effects following short-term exposure to UFPs.

The European Federation of Clean Air and Environmental Protection Associations has recently released a White Paper on "Ambient ultrafine particles: evidence for policy makers" [4] co-authored by an international team of experts that presents updated information on the current knowledge on UFP sources and exposure assessment, and a summary review of available results from toxicological and epidemiological studies. The review highlights the diversity of exposure assessment methods that may affect the consistency of the health associations, the diverse toxicity of UFP in comparison to other PM metrics due to differential deposition patterns and physiochemical characteristics, the lack of a comprehensive updated review on the epidemiological evidence following the growing literature, and the need for regulation in the future. In addition, the White Paper summarised that 164 out of 174 publications included in the previous reviews [4, 8] and published between 1997 to 2017 focused on short-term exposure and investigated a wide variety of associations ranging from mortality to respiratory symptoms.

As part of this consortium, we have undertaken an updated systematic review and meta-analysis of the effects on respiratory morbidity outcomes (defined as hospital admissions and emergency room visits for any respiratory cause) after short-term exposure to UFPs. We thereby followed the indication in the White Paper that there is adequate information to provide a quantitative estimate for these associations for short-term exposure.

\section{Methods}

We followed the guidelines of the Preferred Reporting Items for Systematic Reviews and Meta-Analyses (PRISMA) [10].

\section{Search strategy}

We included articles on respiratory hospital admissions and emergency room visits reported in two previous reviews $[7,8]$, which covered the period from 11 May 2017. We additionally searched PubMed for articles published between 12 May 2017 and 1 March 2019, as well as Web of Science for articles published between 1 January 2000 and 1 March 2019, as the latter database was not searched in the more recent review [8]. We used the same keywords as in the report by OHLwEIN et al. [8] in order to expand their search but limited search terms to respiratory admissions and emergency room visits. Hence we included the following terms: ("Particulate matter" OR "Environmental exposure" OR "Air pollutants" OR "Air pollution" OR "Air pollutant" OR "Air pollutants/adverse effects" OR "Air pollution/adverse effects" OR "Environmental exposure/adverse effects") AND ("Surface area" OR "Ultrafine" OR "Ultrafine particle" OR "Ultrafine particles" OR "Nano particles" OR "Nano particle" OR Nanoparticle OR Nanoparticles OR PM0.1 OR PM0.25 OR PNC OR "Particle Number" OR “Accumulation mode" OR "Aitken mode" OR Submicron*) AND (respirator* OR pulmonary* OR lung OR asthma OR copd) AND 
(infectio* OR disease OR hospitaliz ${ }^{\star}$ OR hospitalis* OR "hospital admission" OR emergency OR morbidit ${ }^{*}$.

\section{Inclusion-exclusion criteria}

We included studies meeting the following criteria: 1) studies with a time-series or case-crossover study design; 2) reporting results on at least one UFP measure/metric recorded as particle number concentration (PNC) or size-fractioned PNC for particles with a lower cut-off point of the size range $<20 \mathrm{~nm} ; 3$ ) investigating the short-term effects of UFP with a maximum lag time of 15 days; 4) studies that reported at least single pollutant model results adjusted for confounders; and 5) studies reported in English.

We excluded studies when: 1) no measure of effect or its precision (sE or confidence interval) was reported; and 2) insufficient information was available to standardise estimates precision (e.g. pollutant increment not clear or results only presented graphically).

When the same study population was used in several publications, we selected the one with the largest sample size or number of events. We excluded previous reports that used the same setting that was also included in following multi-setting studies, as the common protocol in multi-sites is expected to reduce heterogeneity due at least to statistical analysis or outcome definitions. When a paper reported multi-city results, we extracted the city-specific estimates per association. Single-city estimates from multi-city consortia were considered to be of better harmonisation at least considering the definition of health outcomes and city-specific statistical analyses. Following this decision, single-city studies [11-15] that were later part of multi-city consortia were excluded from the meta-analysis that assumes independence between effect estimates that are pooled.

\section{Data extraction}

Data extraction was completed by two independent reviewers (S. Rodopoulou/E. Samoli and M. Renzi/ M. Stafoggia). We extracted information regarding the design, the location and the population of the study, the prevalence of the analysed outcomes, the pollutants considered including descriptive measures, correlations and exposure assessment methods, the statistical analysis and the covariates in the models. When multiple metrics for UFPs were reported we extracted all information and used the metric most closely related to the range of $10-100 \mathrm{~nm}$ in the meta-analysis, to achieve optimal harmonisation among the great variety reported and to address our research hypothesis on the effects of smaller particles. We extracted the reported measures of associations and harmonised them in terms of relative risks, so that the log-transformation of the relative risk per increment was pooled in the meta-analysis. In case odds ratios (ORs) were estimated under a case-crossover design applied in the framework of time-series analysis they were considered equivalent to relative risks obtained through classical time-series models.

\section{Risk of bias assessment}

We adapted criteria for the assessment of risk of bias of observational studies to reflect specific characteristics of time-series and case-crossover designs in our review. More particularly, we rated "yes" as 1 versus "no" as 0,10 relevant aspects of the studies and as a result, the total score of this assessment ranged from $0-10$. Hence we particularly assessed whether: 1) the study design was comprehensibly described; 2) the study population was clearly defined; 3) the prevalence of the outcome was given; 4) the outcome assessment was valid; 5) the exposure assessment was valid; 6) there was a comprehensive description of exposure; 7) the statistical methods were adequate; 8) there was appropriate confounder adjustment; 9) the authors reported multi-pollutant models; and 10) the concentration-response function was given.

\section{Meta-analysis statistical model and heterogeneity investigation}

We meta-analysed city-specific effects for a single outcome only when a minimum of four estimates was available. We applied fixed-effects and random-effects models using the restricted maximum likelihood (REML) method for between-studies variance estimation and the Hartung-Knapp-Sidik-Jonkman correction for the overall variance. It is informative to compare the fixed effect and random effect estimates to evaluate the changes in weights assigned to individual studies especially where the heterogeneity is modest. We further applied sensitivity analysis using the Der Simonian and Laird method for between-studies variance estimation [16]. We assessed heterogeneity by terms of the Q-test and $\mathrm{I}^{2}$ statistic. We reported the summary estimate with associated $95 \%$ CIs, Q-test associated p-value, $\tau^{2}$ and $\mathrm{I}^{2}$ statistics and $95 \%$ prediction intervals. Although UFPs are defined as particles with a diameter $<100 \mathrm{~nm}$, most studies used PNC as a corresponding metric and there were measurement campaigns in three cities (London [17], Barcelona [18] and Rome [18]) when measured PNC was in a range $>100 \mathrm{~nm}$. This is because [19], on the one hand, the existing instrumental methods do not provide information on PNC with a cut-off point of $100 \mathrm{~nm}$. On the other hand, while the choice of the lower window of 
measurement is usually critical, as the majority of UFPs are often within a smaller, lower size range, the upper range is less critical. Effects are expressed as relative risk per 10000 particles $\cdot \mathrm{cm}^{-3}$ increase in PNC for a linear exposure-response association. All analyses were conducted using the metagen package in $\mathrm{R}$ statistical software (version 3.6.0).

We performed several subgroup analyses to investigate potential sources of heterogeneity. Potential effect modifiers considered were: 1) geographical areas (analysis of Western European cities only); 2) diameter range of the underlying exposure UFP metric ( $<100 \mathrm{~nm}$ versus $>100 \mathrm{~nm})$; 3) mean daily level of exposure in a city, defined as $<6000$ particles $\cdot \mathrm{cm}^{-3}$ versus $\geqslant 6000$ particles $\cdot \mathrm{cm}^{-3}$ approximating the median of the mean concentration levels encountered in the city-specific analysis, or as below and above 10000 particles $\mathrm{cm}^{-3}$; 4) type of measurement site (analysis of studies with exposure from only background stations when recorded); and 5) the climate of the area as defined by mean annual temperature below or above $10^{\circ} \mathrm{C}$, where we characterised Barcelona, Beijing, Ljubljana and Rome as cities with hotter climates and Augsburg, Chernivtsi, Copenhagen, Dresden, Helsinki, Prague and Stockholm as cities with cold climates. Between-group comparisons were assessed by Q-test for heterogeneity.

Finally, we assessed associations by season, defined as cool from October to March and warm from April to September.

\section{Results}

Our search in addition to the previous two reviews $[7,8]$ resulted in 73 studies, out of which none was relevant to our association under investigation. More specifically after excluding seven duplicate studies: 19 papers were exposure assessment reports, four studies focused on longer term exposure, 16 studies considered end-points other than respiratory morbidity, 20 studies assessed toxicological end-points, while the remaining seven were air pollution reviews or editorials and letters (figure S1).

Therefore, we proceeded with papers previously identified to provide a quantitative measure for the associations under investigation and explore heterogeneity in the estimates, as preceding reviews were narrative and did not provide meta-analyses.

Nine publications contributed to our review. All studies except one [18] (that followed a case-crossover design) followed a time-series design, covering urban populations over time periods mainly after 2001. The majority of studies reflected results from European cities. There was one study from Beijing, China, [20] three studies [21-23] from the USA and one study from Temuco, Chile [24] (table 1). The papers contributed results from 16 cities on respiratory hospital admissions and emergency room visits. There were two studies from London, UK that reported effects for lag 2 exposure only covering different time periods: one between 2000 and 2005 reporting effects for $0-14$ years and $>65$ years [25], and one between 2011 and 2012 reporting for 0-14 years,15-64 years and $>65$ years [17]. As meta-analysis assumes that independent effect estimates are pooled together, we needed to account for multiple results from London. Hence, for the analysis of all ages, we pooled the three age-specific estimates from SAmoli et al. [17] using a fixed-effects model and the combined estimate was included in the main meta-analyses (only for the corresponding lag 2) to represent effects in the general population of London. For the age-specific analysis, we pooled the effects of the two studies $[17,25]$ for $0-14$ years and $>65$ years before using the pooled effects in our meta-analysis. Results of SincLaIR and Tolsma [21] were not included in the meta-analysis as the effects were reported for surface area. The rest of the studies were generally rated as low risk of bias. We did not meta-analyse effects related to specific diagnoses, as only city-specific results already pooled in SAMOLI et al. [18] reported on asthma, COPD and lower respiratory tract infections for all ages, while the Atlanta study [22] reported on asthma but following cumulative exposure. As only three cities reported on paediatric asthma $[11,15,23]$ we did not pool their results, according to our protocol.

Figure 1 and figure S2 present the results of the meta-analysis for respiratory morbidity end-points (all ages) over lags $0-5$ days, while figure S3 presents the results for lag day 2, also including results of the study from London, as described above. There were no indications for an association in any lag days. The heterogeneity in the estimates between different lags ranged from $0 \%$ in lag day 2 to $71 \%$ in lag day 1 , largely driven by the varying estimates and their large confidence intervals in the cities analysed in the study by LANZINGER et al. [26]. Including London [17] in the lag day 2 analysis did not change the results (figure S3). The results of the random-effects model fitted using the Der Simonian and Laird method were almost identical to those fitted using REML, with only slightly smaller confidence intervals as expected due to the possible underestimation of the between-city variance. For example, the effect estimates on lag day 3 varied from 1.004 (95\% CI 0.991-1.017) under REML to 1.004 (95\% CI 0.991-1.016) under the Der Simonian and Laird method.

Figure 1 (figure S4 for ages 0-14 years) also shows the pooled results for the associations by age group. While the results for age $\geqslant 15$ years are comparable with the results from all ages there is an indication of 


\section{TABLE 1 Description of main characteristics of selected studies}

\begin{tabular}{|c|c|c|c|c|c|c|c|c|}
\hline $\begin{array}{l}\text { First } \\
\text { author } \\
\text { [ref.] }\end{array}$ & Location & $\begin{array}{l}\text { Years of } \\
\text { analysis }\end{array}$ & $\begin{array}{l}\text { Range of } \\
\text { UFP and units }\end{array}$ & $\begin{array}{l}\text { Exposure } \\
\text { method }\end{array}$ & $\begin{array}{l}\text { Exposure mean } \\
\text { and variability }\end{array}$ & $\begin{array}{c}\text { Outcomes } \\
\text { (ICD 9/ICD10) }\end{array}$ & $\begin{array}{l}\text { Lags } \\
\text { considered }\end{array}$ & $\begin{array}{c}\text { Risk } \\
\text { of } \\
\text { bias } \\
\text { score }\end{array}$ \\
\hline SINCLAIR [21] & Atlanta, USA & $1998-2000$ & $\begin{array}{l}10-100 \mathrm{~nm} \\
\left(\mu \mathrm{m}^{2} \cdot \mathrm{cm}^{-3}\right)\end{array}$ & $\begin{array}{l}\text { nano-SMPS, } \\
\text { SMPS, LASAIR }\end{array}$ & $\begin{array}{c}249.33 \\
\pm 244.09 \mu \mathrm{m}^{2} \cdot \mathrm{cm}^{-3}\end{array}$ & $\begin{array}{l}\text { Asthma (ICD9: } \\
\text { 439) visits adults, } \\
\text { children; LRTI } \\
\text { (ICD9: 460-66 } \\
\text { 477, 466.1, } \\
\text { 480-486) adults }\end{array}$ & $\begin{array}{c}\text { Cumulative } \\
\text { lags } 0-2,3- \\
5\end{array}$ & 8 \\
\hline Peel [22] & $\begin{array}{c}\text { Atlanta } \\
\text { metropolitan } \\
\text { area, } \\
\text { Georgia, USA }\end{array}$ & $\begin{array}{c}\text { August } \\
1998- \\
\text { August } \\
2000\end{array}$ & $\begin{array}{c}10-100 \mathrm{~nm} \\
\text { (particles } \cdot \mathrm{cm}^{-3} \text { ) }\end{array}$ & $\begin{array}{c}\text { No } \\
\text { information }\end{array}$ & $\begin{array}{l}38000 \pm 40700 \\
\text { particles } \cdot \mathrm{cm}^{-3}\end{array}$ & $\begin{array}{c}\text { Respiratory } \\
\text { emergency room } \\
\text { visits all ages } \\
\text { (ICD9: } \\
\text { 460-465; 466.0; } \\
480-486 \text {; 491- } \\
493 ; 496 ; 786.09 \text { ) }\end{array}$ & $\begin{array}{c}\text { Cumulative } \\
\text { lags 0-2 }\end{array}$ & 9 \\
\hline LeItTE [20] & Beijing, China & $\begin{array}{l}\text { March } \\
2004- \\
\text { December } \\
2006\end{array}$ & $\begin{array}{c}3-100 \mathrm{~nm} \\
\text { (particles } \cdot \mathrm{cm}^{-3} \text { ) }\end{array}$ & $\begin{array}{c}\text { TSI models } \\
3010,3025, \\
3321\end{array}$ & $\begin{array}{c}22000 \pm 9800 \\
\text { particles } \cdot \mathrm{cm}^{-3}\end{array}$ & $\begin{array}{c}\text { Selected } \\
\text { respiratory } \\
\text { emergency room } \\
\text { visits all ages } \\
\text { (ICD10: J00-J06; } \\
\text { J18; J20; J30- } \\
\text { J39;J40-J47) }\end{array}$ & $\begin{array}{c}\text { Individual } \\
\text { lags } 0-5 \text {, } \\
\text { Cumulative } \\
\text { lags } 0-1,0- \\
2,0-3,0-4 \\
0-5\end{array}$ & 8 \\
\hline $\begin{array}{l}\text { Díaz-Robles } \\
\text { [24] }\end{array}$ & $\begin{array}{l}\text { Temuco, } \\
\text { Chile }\end{array}$ & 2009-2011 & Missing & $\begin{array}{c}\text { MOUDI } \\
\text { 100-NR model }\end{array}$ & $8(4.73) \mu \mathrm{g} \cdot \mathrm{m}^{-3}$ & $\begin{array}{l}\text { All respiratory } \\
\text { admissions } \\
\text { (ICD10: J00-J99) } \\
\text { <5 years; } \\
\text { 5-64 years; } \\
\text { >65 years; other } \\
\text { respiratory } \\
\text { admissions } \\
\text { (ICD10: missing) } \\
\text { <5 years; } \\
\text { >65 years }\end{array}$ & $\begin{array}{l}\text { Individual } \\
\text { lags } 0-5\end{array}$ & 4 \\
\hline Evans [23] & $\begin{array}{l}\text { New York, } \\
\text { USA }\end{array}$ & 2006-2009 & $\begin{array}{c}10-100 \mathrm{~nm} \\
\text { (particles } \cdot \mathrm{cm}^{-3} \text { ) }\end{array}$ & TSI & $\begin{array}{c}5151 \pm 2359 \\
\text { particles } \cdot \mathrm{cm}^{-3}\end{array}$ & $\begin{array}{l}\text { Asthma visits } \\
\text { (ICD: missing) } \\
\text { children } \\
\text { 3-10 years }\end{array}$ & $\begin{array}{l}\text { Individual } \\
\text { lags } 1-7\end{array}$ & 7 \\
\hline SAMOLI [18] & $\begin{array}{l}\text { Barcelona, } \\
\text { Spain }\end{array}$ & $2005-2010$ & $\begin{array}{c}5-1000 \mathrm{~nm} \\
\left(\text { particles } \cdot \mathrm{cm}^{-3} \text { ) }\right.\end{array}$ & TSI WCPC3785 & $\begin{array}{c}19554 \pm 8044 \\
\text { particles } \cdot \mathrm{cm}^{-3}\end{array}$ & $\begin{array}{l}\text { All respiratory } \\
\text { admissions } \\
\text { (ICD10: J00-J99) } \\
\text { all ages; } \\
0-14 \text { years, } \\
\text { 15-64 years, } \\
65 \text { years; } \\
\text { Asthma (ICD10: J } \\
\text { 45) all ages; LRTI } \\
\text { (ICD 10: J09-J18, } \\
\text { J20-J22) all ages; } \\
\text { COPD (ICD10: } \\
\text { J40-J44, J47) all } \\
\text { ages }\end{array}$ & $\begin{array}{l}\text { Individual } \\
\text { lags } 0-10\end{array}$ & 10 \\
\hline
\end{tabular}




\section{TABLE 1 Continued}

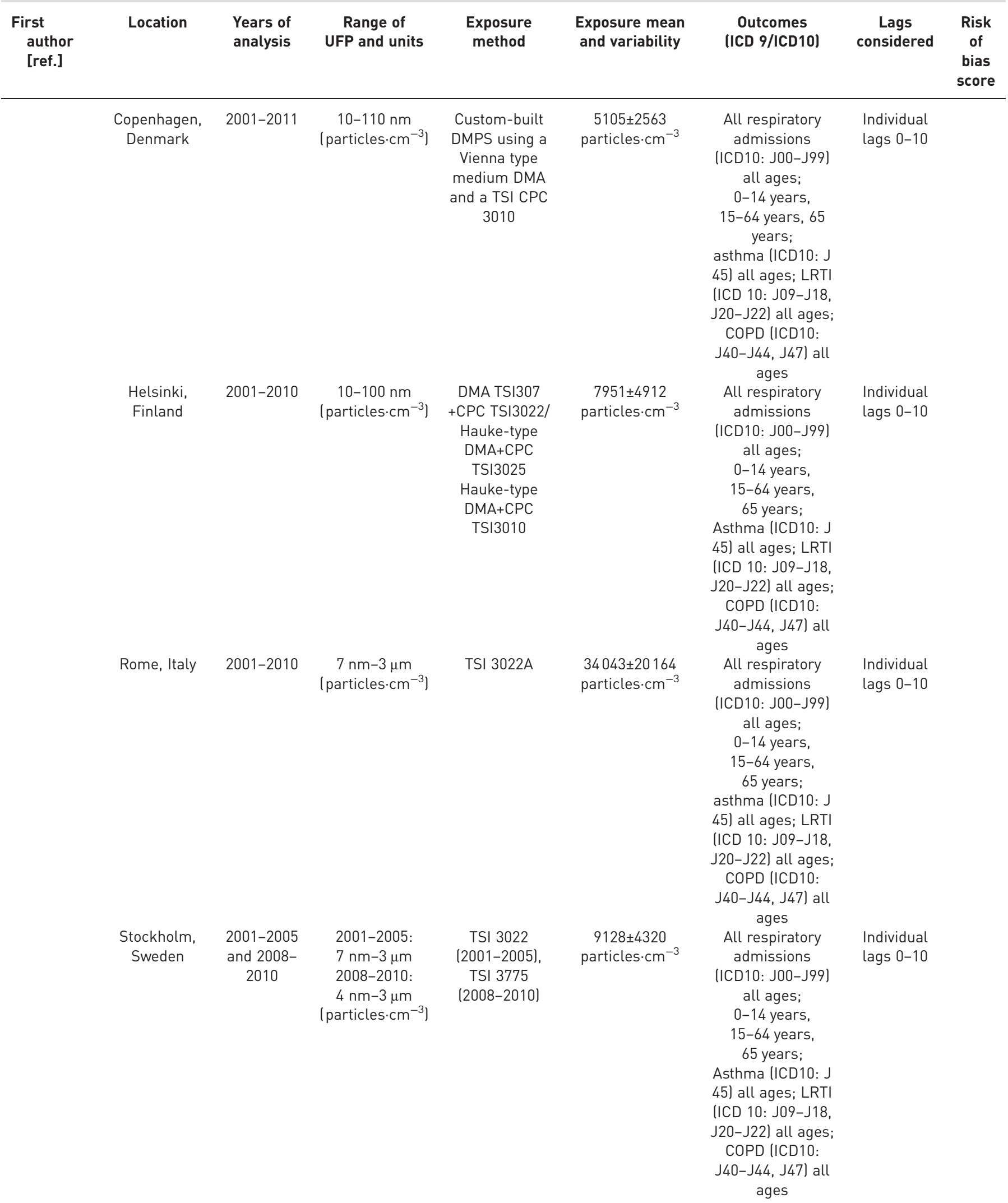




\begin{tabular}{|c|c|c|c|c|c|c|c|c|}
\hline $\begin{array}{l}\text { First } \\
\text { author } \\
\text { [ref.] }\end{array}$ & Location & $\begin{array}{l}\text { Years of } \\
\text { analysis }\end{array}$ & $\begin{array}{c}\text { Range of } \\
\text { UFP and units }\end{array}$ & $\begin{array}{l}\text { Exposure } \\
\text { method }\end{array}$ & $\begin{array}{l}\text { Exposure mean } \\
\text { and variability }\end{array}$ & $\begin{array}{l}\text { Outcomes } \\
\text { (ICD } 9 / \text { ICD10) }\end{array}$ & $\begin{array}{l}\text { Lags } \\
\text { considered }\end{array}$ & $\begin{array}{c}\text { Risk } \\
\text { of } \\
\text { bias } \\
\text { score }\end{array}$ \\
\hline SAMOLI [17] & London, UK & $2011-2012$ & $\begin{array}{c}7 \mathrm{~nm}-3 \mu \mathrm{m} \\
\text { (particles } \cdot \mathrm{cm}^{-3} \text { ) }\end{array}$ & TSI 3022 & $\begin{array}{c}\text { Missing } \\
(\text { IQR } 5180 \\
\left.\text { particles } \cdot \mathrm{cm}^{-3}\right)\end{array}$ & $\begin{array}{l}\text { All respiratory } \\
\text { admissions } \\
\text { (ICD10: J00-J99) } \\
\text { 0-14 years; } \\
\text { 15-64 years; } \\
65+\text { years; }\end{array}$ & $\operatorname{Lag} 2$ & 8 \\
\hline \multirow[t]{3}{*}{$\begin{array}{l}\text { LANZINGER } \\
\text { [26] }\end{array}$} & $\begin{array}{l}\text { Augsburg, } \\
\text { Germany }\end{array}$ & $2011-2012$ & $\begin{array}{c}20-100 \mathrm{~nm} \\
\text { (particles } \cdot \mathrm{cm}^{-3} \text { ) }\end{array}$ & DMPS/SMPS & $\begin{array}{c}5880 \pm 3016 \\
\text { particles } \cdot \mathrm{cm}^{-3}\end{array}$ & $\begin{array}{l}\text { All respiratory } \\
\text { admissions all } \\
\text { ages, > and } \\
<75 \text { years (ICD10: } \\
\text { J00-J99) }\end{array}$ & $\begin{array}{c}\text { Individual } \\
\text { lags } 0-5, \\
\text { Cumulative } \\
\text { lags } 01,25 \text {, } \\
05\end{array}$ & 10 \\
\hline & $\begin{array}{l}\text { Dresden, } \\
\text { Germany }\end{array}$ & $2011-2012$ & $\begin{array}{c}20-100 \mathrm{~nm} \\
\text { (particles } \cdot \mathrm{cm}^{-3} \text { ) }\end{array}$ & DMPS/SMPS & $\begin{array}{c}4286 \pm 2339 \\
\text { particles } \cdot \mathrm{cm}^{-3}\end{array}$ & $\begin{array}{l}\text { All respiratory } \\
\text { admissions all } \\
\text { ages, > and } \\
\text { <75 years (ICD10: } \\
\text { J00-J99) }\end{array}$ & $\begin{array}{c}\text { Individual } \\
\text { lags } 0-5, \\
\text { Cumulative } \\
\text { lags } 01,25 \text {, } \\
05\end{array}$ & \\
\hline & $\begin{array}{l}\text { Ljubljana, } \\
\text { Slovenia }\end{array}$ & $2012-2013$ & $\begin{array}{c}20-100 \mathrm{~nm} \\
\left(\text { particles } \cdot \mathrm{cm}^{-3} \text { ) }\right.\end{array}$ & DMPS/SMPS & $\begin{array}{c}4693 \pm 1897 \\
\text { particles } \cdot \mathrm{cm}^{-3}\end{array}$ & $\begin{array}{l}\text { All respiratory } \\
\text { admissions all } \\
\text { ages, > and } \\
<75 \text { years (ICD10: } \\
\text { J00-J99) }\end{array}$ & $\begin{array}{c}\text { Individual } \\
\text { lags } 0-5 \text {, } \\
\text { Cumulative } \\
\text { lags } 01,25 \text {, } \\
05\end{array}$ & \\
\hline
\end{tabular}

Data are presented as mean \pm SD or median (interquartlie range), unless otherwise stated. UFP: ultrafine particles; TSI: Thermo-Systems Engineering Co.; LRTI: lower respiratory tract infections; DMPS: differential mobility particle sizer; DMA: differential mobility analyzer; CPC: condensation particle counter; SMPS: scanning mobility particle sizer; ICD: International Classification of Diseases.

an association in the age group 0-14 years for individual lags up to lag 5, that reached statistical significance for lags 2 and 3 (relative risk 1.01, 95\% CI 1.00-1.02). Not all cities contributed results in the age-specific analyses, therefore, this analysis only included Western European cities [18, 25]. Further, we assessed the association for the age 15-64year group for lag 2 with and without London [17] to include the same number of cities across lags (as London contributed effect estimates only for lag 2). The results were robust to the inclusion of London as the pooled relative risk remained 1.00 (95\% CI 0.99-1.02) in both cases. We tested the robustness of our finding in the age 0-14 year group by further including results from Evans et al. [23] who reported association for asthma among children aged 3-10 years in New York, USA. and the estimates were identical, due to the small weight of the study (figure S4).

Due to the large heterogeneity in the exposure metrics, we performed several subgroup meta-analyses to test the robustness of our findings. Table 2 presents the pooled relative risk (and corresponding 95\% CIs) and heterogeneity measures for several subgroups meta-analyses for a 10000 particles $\cdot \mathrm{cm}^{-3}$ increase in lag 3 exposure, as the main analysis indicated small nonsignificant associations following lag 2 . Results were robust when limited to Western European cities or cities that characterised the fixed monitoring station as urban background, as well as to climate, the size of the particles measured by each exposure monitoring campaign or to the mean daily levels in each city. Despite robust results, heterogeneity was greatly reduced for effect estimates corresponding to a more homogenous exposure metric defined by diameter size $(<100 \mathrm{~nm})$ or to overall low concentration levels. Interestingly, for mean city-specific levels $<6000$ particles $\cdot \mathrm{cm}^{-3}$ (as in Augsburg, Copenhagen, Chernivtsi, Dresden, Ljubljana and Prague; whereas $\geqslant 6000$ particles $\cdot \mathrm{cm}^{-3}$ were observed in Beijing, Barcelona, Helsinki, Rome and Stockholm) a statistically 


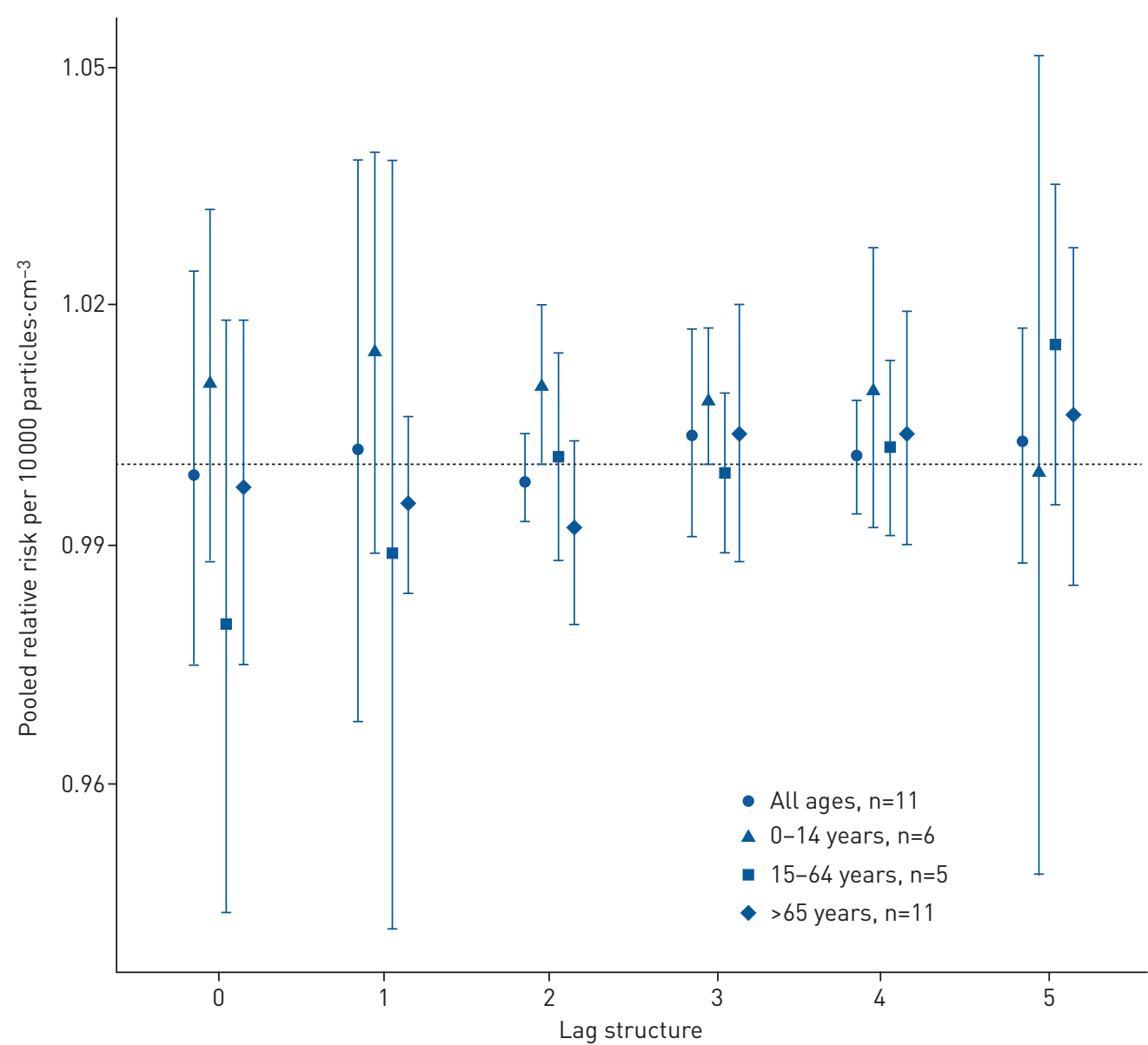

FIGURE 1 Pooled relative risks land associated $95 \%$ confidence intervals) from random-effects meta-analysis for respiratory morbidity associated with a 10000 particles. $\mathrm{cm}^{-3}$ increase in particle number concentrations overall and by age group. $\mathrm{N}$ indicates the number of cities included in the meta-analysis.

TABLE 2 Pooled relative risks land associated $95 \% \mathrm{Cl}$ ) and heterogeneity measures $\left(\mathrm{I}^{2}\right.$ and $\mathrm{Q}$-value) from random-effects models for the association between respiratory admissions following a 10000 particles $\mathrm{cm}^{-3}$ increase in lag 3 particle number concentration (PCN) by city characteristics

\begin{tabular}{|c|c|c|c|c|}
\hline Characteristic & Cities $\mathrm{n}$ & $\begin{array}{l}\text { Relative risk } \\
\text { (95\% CI) }\end{array}$ & $\begin{array}{c}\mathrm{I}^{2} \% \\
\text { (Q p-value) }\end{array}$ & $\begin{array}{l}\mathrm{p} \text {-value for between } \\
\text { groups difference }\end{array}$ \\
\hline Western European cities only & 8 & $1.00(0.99-1.00)$ & $58(0.028)$ & Not applicable \\
\hline \multicolumn{5}{|l|}{ Upper limit of particle size } \\
\hline$<100 \mathrm{~nm}$ & 8 & $1.00(0.97-1.03)$ & $2(0.417)$ & 0.519 \\
\hline$>100 \mathrm{~nm}$ & 3 & $1.01(0.98-1.04)$ & $75(0.017)$ & \\
\hline$>6000$ particles $\cdot \mathrm{cm}^{-3}$ & $\begin{array}{c}5 \text { (Beijing, Barcelona, Helsinki, Rome, } \\
\text { Stockholm) }\end{array}$ & $1.00(0.98-1.02)$ & $66(0.020)$ & \\
\hline \multicolumn{5}{|l|}{ By mean daily levels of PNC" } \\
\hline$<10000$ particles $\cdot \mathrm{cm}^{-3}$ & 8 & $1.01(0.99-1.03)$ & $7(0.375)$ & 0.604 \\
\hline$>10000$ particles $\cdot \mathrm{cm}^{-3}$ & 3 & $1.00(0.96-1.05)$ & $74(0.020)$ & \\
\hline
\end{tabular}

\#: below or above the median of the contributing cities' levels; " : for comparability with previous results. 


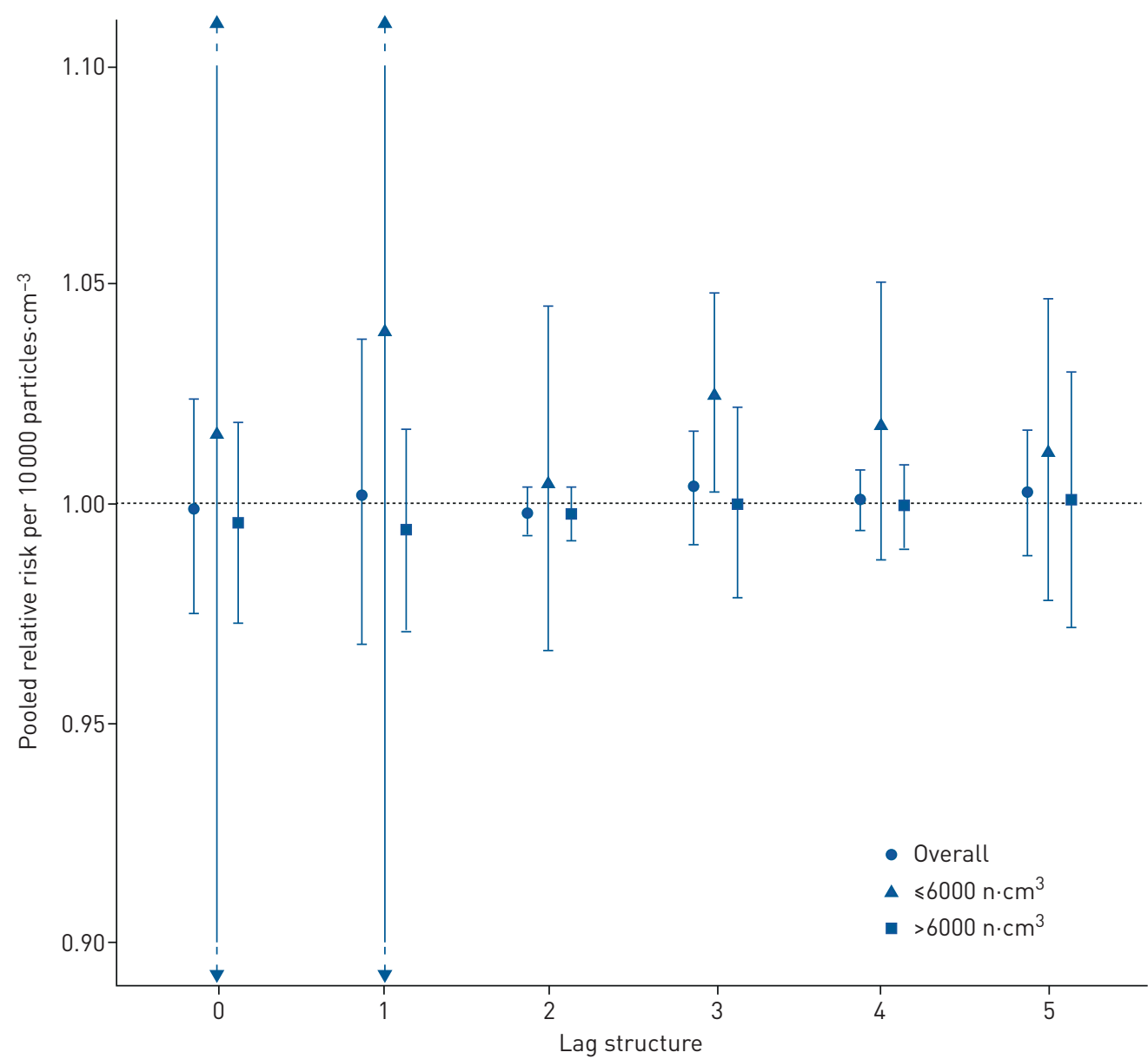

FIGURE 2 Pooled relative risks land associated $95 \%$ confidence intervals) from random-effects meta-analysis for respiratory hospital admissions associated with a 10000 particles $\cdot \mathrm{cm}^{-3}$ increase in particle number concentrations overall and by mean levels of ultrafine particles.

significant increase in respiratory morbidity was detected (relative risk 1.03 per 10000 particles $\cdot \mathrm{cm}^{-3}$ increase, 95\% CI 1.00-1.05).

Figure 2 and figure S5 show the pooled results for the respiratory hospital admissions for all ages overall and by city-specific levels indicating the consistency of the association $<6000$ particles $\cdot \mathrm{cm}^{-3}$ across lags. Figure 3 shows the pooled results for the respiratory hospital admission for all ages overall and by season for 10 cities that contributed data. Specifically, SAmoli et al. [18] and LANZINGER et al. [26] reported effect estimates separately for the warm and cool periods of the year for lags 0 to 5 . We found consistently statistically significant associations following lag 2 exposure during the warm period. Indicatively a 10000 particles $\cdot \mathrm{cm}^{-3}$ increase in lag 3 exposure was associated with a relative risk of 1.04 (95\% CI 1.03-1.05) in respiratory admission for all ages versus a relative risk of 1.00 (95\% CI 0.98-1.01) for the cold period.

Figure 4 includes forest plots for the associations with increases in lag 3 PNC for all ages, ages 0-14 years, the warm period and by city mean PNC level to highlight the consistency of the associations between areas for those aged 0-14 years, in the warm period and in cities with mean levels $<6000$ particles $\cdot \mathrm{cm}^{-3}$. Heterogeneity measures should be read with caution due to the large confidence intervals of Eastern European cities.

\section{Discussion}

We undertook a systematic review and meta-analyses on the respiratory effects following short-term exposure to UFPs to update previous reports $[7,8]$ and contribute to the discussion in view of the World Health Organization review of air quality guidelines. We were unable to detect a significant association for respiratory morbidity across all ages, but our analysis indicates associations during the warm period of the year at longer lags, and a small effect estimate for children aged 0-14 years and in cities with a mean daily level of UFPs $<6000$ particles $\cdot \mathrm{cm}^{-3}$. The latter may imply a supra-linear shape with a plateau following a 


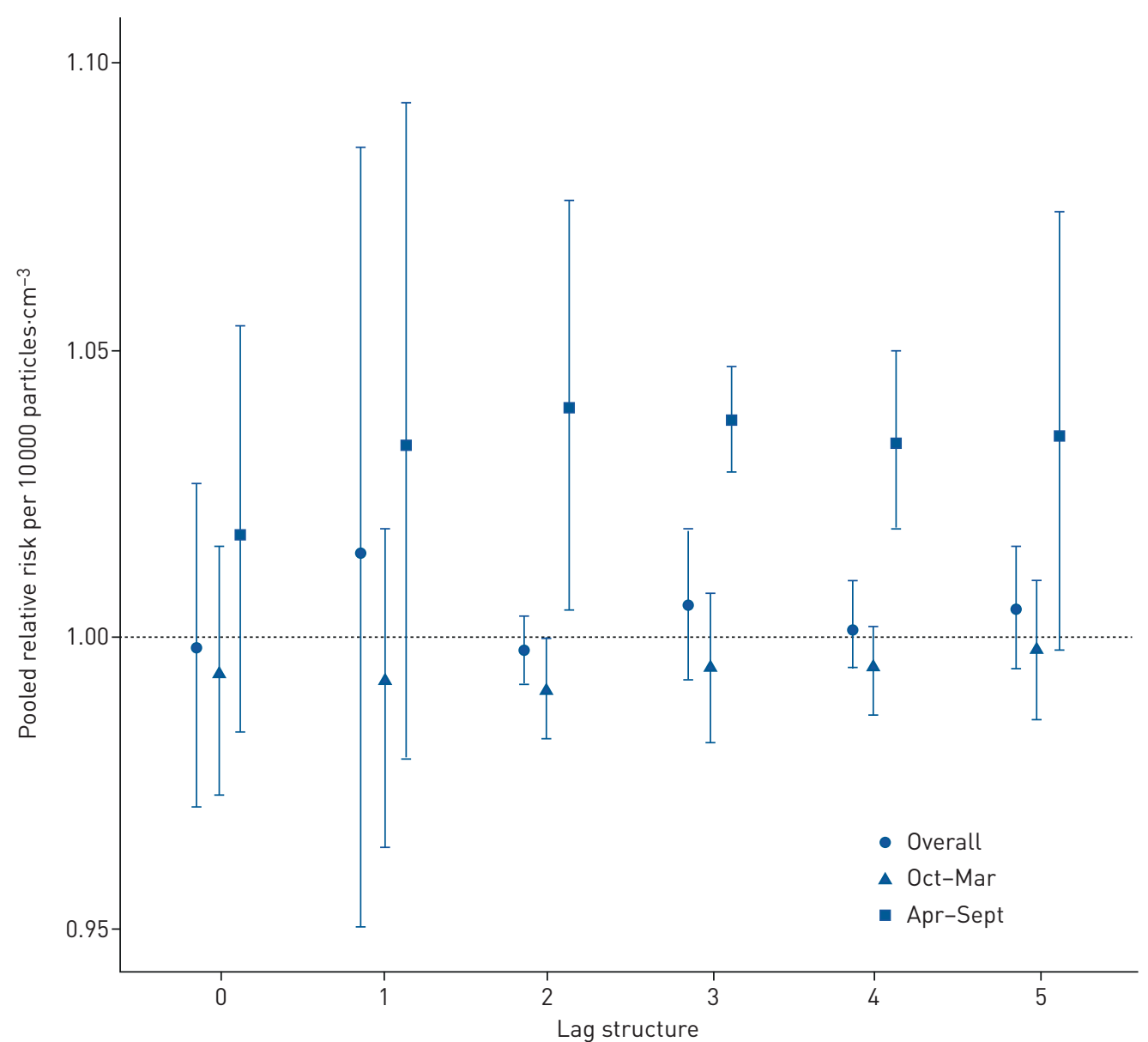

FIGURE 3 Pooled relative risks land associated $95 \%$ confidence intervals) from random-effects meta-analysis for respiratory hospital admissions associated with a 10000 particles $\cdot \mathrm{cm}^{-3}$ increase in particle number concentrations overall and by season in 10 European cities.

threshold that would downscale the linear effect estimate if the whole concentration range is analysed without considering this deviation from linearity.

Previous meta-analyses have reported associations of UFPs on paediatric respiratory morbidity. For example, SAmoli et al. [18] reported consistent adverse effect estimates on respiratory admissions for children aged $0-14$ years, with the strongest association at lag 7 (1.60\% increase, 95\% CI $0.49-2.72 \%$ for 10000 particles $\cdot \mathrm{cm}^{-3}$ increase in PNC). A recent meta-analysis by Li et al. [27] reported that an increase of 10000 particles $\cdot \mathrm{cm}^{-3}$ was associated with an increase in paediatric asthma exacerbation (OR 1.070, 95\% CI 1.037-1.104), asthma emergency department visits (OR 1.111, 95\% CI: 1.055-1.170), and in asthmaassociated hospital admissions (OR 1.045, 95\% CI: 1.004-1.088), while again estimates were larger at longer lags. Respiratory hospital admissions in children are often asthma-related. These effects may be partly driven by pollen or outdoor mould concentrations that present strong seasonal patterns. As the studies contributing on these associations did not provide information or model adjustment (due to lack of relevant data) it is unclear which part of the effect estimates may be independent of these. Nonetheless, studies focusing on air pollution effects on lung function growth have consistently identified detrimental effects supporting mechanisms affecting children's respiratory health [28].

Although our results are comparable with previous reports [18, 27], we must stress the large heterogeneity in the reported exposure metrics due to the exposure assessment methods used and the reported metrics. Almost each exposure campaign applied a different measurement method (differential mobility particle sizer, several Thermo-Systems Engineering Co. models, scanning mobility particle sizer). Different measuring campaigns may have partly contributed to the observed heterogeneity. Nonetheless this will most probably lead to differences in magnitude but not direction, while a more likely limitation is that measurements at a single site (as was the case in most cities) reflect the overall pattern in the city less well than for pollutants routinely measured such as larger particles and nitrogen dioxide $\left(\mathrm{NO}_{2}\right)$. Our review clearly highlights the need for expanded measurement campaigns with longer time-series and multiple 
a)

$\begin{array}{ll}\text { Author [ref.] } & \text { Location } \\ & \\ \text { LANZINGER [26] } & \text { Augsburg } \\ \text { LANZINGER [26] } & \text { Chernivtsi } \\ \text { LANZINGER [26] } & \text { Dresden } \\ \text { LANZINGER [26] } & \text { Ljubljana } \\ \text { LANZINGER [26] } & \text { Prague } \\ \text { LEITTE [20] } & \text { Beijing } \\ \text { SAMOLI [18] } & \text { Barcelona } \\ \text { SAMOLI [18] } & \text { Cophenhagen } \\ \text { SAMOLI [18] } & \text { Helsinki } \\ \text { SAMOLI [18] } & \text { Rome } \\ \text { SAMOLI [18] } & \text { Stockholm } \\ \text { Fixed effect model } \\ \text { Random effects model } \\ \text { Prediction interval } \\ \text { Heterogeneity: }\left.\right|^{2}=36 \%, \tau^{2}=0.0001, p=0.11\end{array}$

b)

\begin{tabular}{ll} 
Author [ref.] & Location \\
& \\
SAMOLI [18] & Barcelona \\
SAMOLI [18] & Cophenhagen \\
SAMOLI [18] & Helsinki \\
SAMOLI [18] & Rome \\
SAMOLI [18] & Stockholm \\
ATKINSON [25] & London \\
\multicolumn{2}{l}{ Fixed effect model } \\
Random effects model \\
Prediction interval \\
Heterogeneity: $I^{2}=0 \%, \tau^{2}=0, p=0.80$
\end{tabular}

c)

Author [ref.]

LANZINGER [26]

LANZINGER [26]

LANZINGER [26]

LANZINGER [26]

LANZINGER [26]

SAMOLI [18]

SAMOLI [18]

SAMOLI [18]

SAMOLI [18]

SAMOLI [18]

Fixed effect model

Random effects model

Prediction interval

Heterogeneity: $\left.\right|^{2}=0 \%, \tau^{2}=0, p=0.94$

d)

Author [ref.] Location

Mean PNC levels $\leqslant 6000 \mathrm{n} \cdot \mathrm{cm}^{-3}$
LANZINGER [26] Augsburg

LANZINGER [26] Chernivtsi

LANZINGER [26] Chernivtsi

$\begin{array}{ll}\text { LANZINGER [26] } & \text { Dresden } \\ \text { LANZINGER [26] } & \text { Ljubljana }\end{array}$

LANZINGER [26] Prague

SAMOLI [18] Cophenhagen

Fixed effect model

Random effects model

Heterogeneity: $\left.\right|^{2}=0 \%, \tau^{2}=0, p=0.916$

Mean PNC levels $>6000 \mathrm{n} \cdot \mathrm{cm}^{-3}$

LEITTE [26] China

SAMOLI [18] Barcelona

SAmoli [18] Helsink

SAMOLI [18] Rome

SAMOLI [18] Stockholm

Fixed effect model

Random effects model

Heterogeneity: $\mathrm{I}^{2}=66 \%, \tau^{2}=0.0002, \mathrm{p}=0.020$

Fixed effect model

Random effects model

Heterogeneity: $\left.\right|^{2}=36 \%, \tau^{2}=0.0001, p=0.109$

Residual heterogeneity: $\left.\right|^{2}=31 \%, p=0.1580 .8$

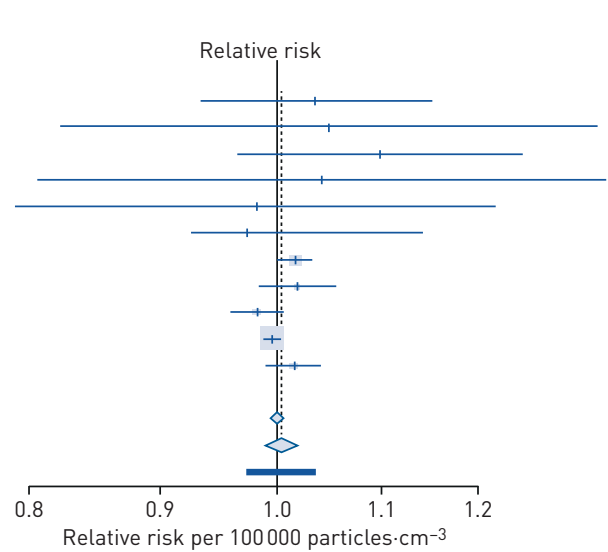

Weight Weight

$1.04(0.93-1.15) \quad 0.3 \% \quad 1.5 \%$

$1.05(0.82-1.34) \quad 0.1 \% \quad 0.3 \%$

$1.10(0.97-1.25) \quad 0.2 \% \quad 1.0 \%$

$1.04(0.81-1.35) \quad 0.1 \% \quad 0.3 \%$

$0.98(0.79-1.22) \quad 0.1 \% \quad 0.4 \%$

$0.97(0.93-1.02) \quad 1.5 \% \quad 6.0 \%$

$1.02(1.00-1.03) \quad 14.9 \% \quad 21.9 \%$

$1.02(0.98-1.06) \quad 2.9 \% \quad 9.9 \%$

$0.98(0.96-1.01) \quad 6.2 \% \quad 15.6 \%$

$1.00(0.99-1.00) \quad 68.3 \% \quad 28.5 \%$

$1.02(0.99-1.04) \quad 5.6 \% \quad 14.7 \%$

$1.00(0.99-1.01) \quad 100.0 \%$

$1.00(0.99-1.02)$

(0.97-1.03)

$100.0 \%$

Weight Weight

RR $(95 \% \mathrm{Cl}$ (fixed) (random

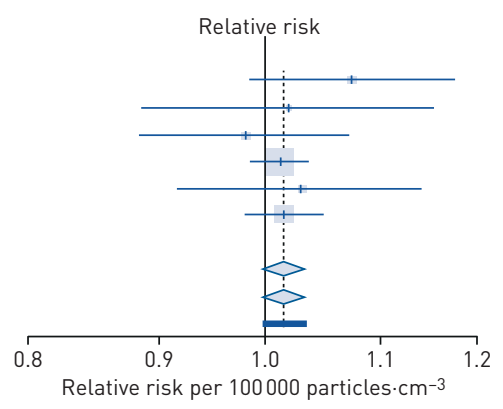

$1.04(0.99-1.09)$ $1.01(0.95-1.08)$

$0.99(0.95-1.04)$

$1.01(0.99-1.02)$

$1.02(0.96-1.07)$

$1.01(0.99-1.03)$

$1.01(1.00-1.02)$

$1.01(1.00-1.02)$

(1.00-1.02)

$4.2 \% \quad 4.2 \%$

$2.1 \% \quad 2.1 \%$

$4.0 \% \quad 4.0 \%$

$57.3 \% \quad 57.3 \%$

$3.0 \% \quad 3.0 \%$

$29.5 \% \quad 29.5 \%$

$100.0 \%$

$100.0 \%$

Weight Weight

$\begin{array}{ccc}\text { RR }(95 \% \mathrm{CI}) & \text { (fixed) } & \text { (random) } \\ 1.00(0.83-1.19) & 0.5 \% & 0.5 \%\end{array}$

$0.92(0.58-1.46) \quad 0.1 \% \quad 0.1 \%$

$1.05(0.91-1.22) \quad 0.7 \% \quad 0.7 \%$

$1.13(0.79-1.62) \quad 0.1 \% \quad 0.1 \%$

$1.04(0.78-1.39) \quad 0.2 \% \quad 0.2 \%$

$1.04(1.01-1.06) \quad 29.4 \% \quad 29.4 \%$

$1.08(1.02-1.14) \quad 4.6 \% \quad 4.6 \%$

$1.04(0.99-1.08) \quad 8.4 \% \quad 8.4 \%$

$1.03(1.02-1.05) \quad 50.5 \% \quad 50.5 \%$

$1.06(1.01-1.12) \quad 5.5 \% \quad 5.5 \%$

$1.04(1.03-1.05) \quad 100.0 \%$

$1.04(1.03-1.05)$

(1.03-1.05)

$100.0 \%$

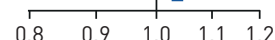

Relative risk per 100000 particles $\cdot \mathrm{cm}^{-3}$

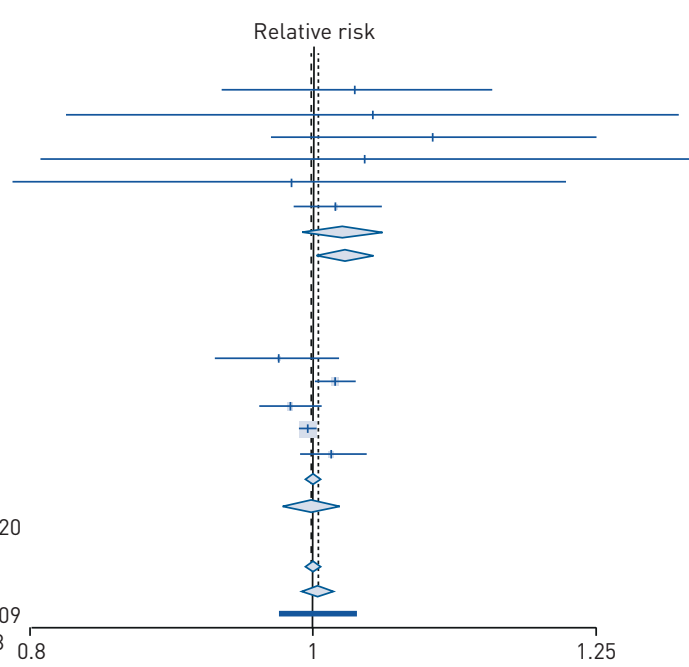

$\operatorname{RR}(95 \% \mathrm{Cl})$

Weight Weight

(fixed) (random)

$1.04(0.93-1.15) \quad 0.3 \% \quad 1.5 \%$

$1.05(0.82-1.34) \quad 0.1 \% \quad 0.3 \%$

$1.10(0.97-1.25) \quad 0.2 \% \quad 1.0 \%$

$\begin{array}{lll}1.104(0.81-1.35) & 0.1 \% & 0.3 \%\end{array}$

$\begin{array}{lll}1.04(0.81-1.35) & 0.1 \% & 0.3 \% \\ 0.98(0.79-1.22) & 0.1 \% & 0.4 \%\end{array}$

$\begin{array}{lll}1.02(0.98-1.06) & 2.9 \% & 9.9 \%\end{array}$

$\begin{array}{lll}1.03(0.99-1.06) & 3.6 \% & \\ 1.03(1.00-1.05) & & 13.3 \%\end{array}$

$0.97(0.93-1.02) \quad 1.5 \% \quad 6.0 \%$

$1.02(1.00-1.03) \quad 14.9 \% \quad 21.9 \%$

$0.98(0.96-1.01) \quad 6.2 \% \quad 15.6 \%$

$1.00(0.99-1.00) \quad 68.3 \% \quad 28.5 \%$

$\begin{array}{lll}1.02(0.99-1.04) & 5.6 \% & 14.7 \%\end{array}$

$1.00(0.99-1.00) \quad 96.4 \% \quad 86.7 \%$

$1.00(0.98-1.02) \quad 86.7 \%$

$1.00(0.99-1.01) \quad 100.0 \%$

$1.00(0.99-1.02) \quad 100.0 \%$

(0.97-1.03)

Relative risk per 100000 particles $\cdot \mathrm{cm}^{-3}$

FIGURE 4 Individual study and pooled relative risks land associated $95 \% \mathrm{Cl}$ ) from random-effects meta-analysis associated with a 10 000 particles $\cdot \mathrm{cm}^{-3}$ increase in lag 3 particle number concentrations on respiratory morbidity for al all ages, b) 0-14 years old, c) April to September (warm) season and d) by mean daily levels of particle number concentration (PNC) (below or above 6000 particles. $\mathrm{cm}^{-3}$ ). 
measurement sites to allow more powerful studies. Previous reviews have also reported the difficulty in combining information from multiple studies due to the wide differences in exposure assessment methods [29]. The comparison of results from different studies is even harder considering their use of various exposure periods, age groups and respiratory morbidity indexes.

Our extensive sensitivity analyses, possibly due to the small number of city-specific results, indicated robust estimates but also effect estimates for cities with mean UFP concentrations $<6000$ particles $\cdot \mathrm{cm}^{-3}$. There were not enough studies in the reported paediatric associations to explore heterogeneity and potential publication bias. The limited number of studies also prohibited further investigation of possible effect modifiers. Indicatively although we initially planned to test for a change in effects due to the introduction of low sulphur fuel around 2006 in North America and Europe, the great majority of the measurement campaigns were either after 2006 or covered a prolonged time-series that did not allow differentiation.

We further report statistically significant effect estimates during the warm period of the year following lag 2 exposure in 10 European cities. These are attributed to the higher effect estimates reported in Western European cities by SAMOLI et al. [18], as in these five cities for the warm season a 10000 particles $\cdot \mathrm{cm}^{-3}$ increase in PNC was associated with an increase in respiratory admissions for all ages $>2.5 \%$, for exposures longer than lag 2, which were all statistically significant. In their analysis, the estimates among children aged 0-14 years were also larger in the warm period and almost above $5 \%$ in all lags (and statistically significant for most lags). However, in the five smaller Central Eastern European cities analysed by LANZINGER et al. [26] there were no seasonal differences in UFP respiratory effect estimates. The higher associations between UFP concentrations and respiratory health in the warm period may be attributed to better exposure characterisation of the population or differences in particle composition. The latter is more complicated, as the UFP composition changes due to varying source contributions as well as atmospheric chemistry and may also partly explain the heterogeneous results between Western [18] and Central Eastern [26] European cities. The higher estimates in the warm season may be further attributed to higher indoor penetration of UFPs due to open windows, as generally their penetration is poorer compared to larger particles.

As UFPs in cities are mainly attributed to tailpipe emissions (which include primary particles emitted directly by vehicles and secondary particles formed in the air from the gaseous precursors emitted by vehicles) and considered traffic-related, we initially wanted to investigate the association controlling for other pollutants such as $\mathrm{PM}_{2.5}$ or $\mathrm{NO}_{2}$. Among the selected studies, SAmoli et al. [18] and LANZinger et al. [26] reported effect estimates of two-pollutant models for different exposure periods (single lags versus cumulative lags, correspondingly) that did not allow for their meta-analysis, but in both cases, there were indications of confounding on analysis for all ages of admissions. In the analyses of SAmoli et al. [18], the associations for the two-pollutant models decreased but nevertheless remained in the same direction for all ages. The authors did not show paediatric admission estimates adjusting for other pollutants but decreased, but still significant, effect estimates in the warm season controlling for $\mathrm{NO}_{2}$ and carbon monoxide. LANZINGER et al. [26] only reported on 6 days average estimates from two-pollutant models for all ages for respiratory admissions, so again the results are not directly transferable to our discussion on children or the warm period.

Particle inhalation has been associated with releases in pro-inflammatory mediators or vasculo-active molecules from lung cells causing systemic oxidative stress and inflammation [26]. Biological mechanisms associated with particle inhalation may differ between UFPs and larger particles. This may be partly due to their deeper penetration into the lungs due to their small size as they more easily escape natural defence mechanisms, but also due to greater biological reactivity and surface area $[3-6,26]$.

Our report reveals that the evidence is still weak for epidemiological findings on UFP respiratory effects almost two decades after the first relevant publication. The related exposure data are still sparse and diverse, as the exposure campaigns in the cities included in our analyses only used one fixed station (most commonly a background one). This may bias the associations by inducing larger measurement error as compared to other pollutants such as $\mathrm{PM}_{2.5}$ that are routinely monitored at a larger number of stations throughout the cities and hence better represent population exposure. Moreover, it has been discussed that UFPs have a larger spatial and temporal variability than fine particles due to their different physical properties [30]. Additionally, we focused our meta-analysis on health effects of short-term exposure due to the White Paper indication [5] on an adequate number of previous studies for a quantitative review and not based on prior causality mechanisms between short-term exposures and respiratory morbidity. Although studies on long-term exposures to UFPs are more complex and require more resources, it is possible that long-term exposures may be more relevant to associated effects, especially nonrespiratory ones. Indicatively, CLIFFORD et al. [31] in a cross-sectional study among children aged 8-11 years reported 
a positive association between UFPs and a biomarker for systemic inflammation but not with respiratory markers. We call upon future researchers to harmonise exposure assessment methods and expand campaigns in order to optimise epidemiological study settings, allow for multicentre studies and better inform future policies.

Conflict of interest: E. Samoli has nothing to disclose. S. Rodopoulou has nothing to disclose. A. Schneider reports grants from German Environment Agency, German Foundation of Heart Research, German Federal Ministry of Education and Research and US Environmental Protection Agency, outside the submitted work. L. Morawska has nothing to disclose. M. Stafoggia has nothing to disclose. M. Renzi has nothing to disclose. S. Breitner reports grants from German Environment Agency and US Environmental Protection Agency, outside the submitted work. T. Lanki has nothing to disclose. R. Pickford reports grants from Interreg Central Europe, outside the submitted work. T. Schikowski has nothing to disclose. E. Okokon has nothing to disclose. S. Zhang has nothing to disclose. Q. Zhao has nothing to disclose. A. Peters has nothing to disclose.

Support statement: There was no third-party funding for this work and the study has been conducted as a collaborative effort.

\section{References}

1 World Health Organization. Review of evidence on health aspects of air pollution - REVIHAAP project: final technical report. www.euro.who.int/_data/assets/pdf_file/0004/193108/REVIHAAP-Final-technical-report-finalversion.pdf?ua=1 Date last accessed: 18 November 2019; date last updated: 2013.

2 Kim KH, Kabir E, Kabir S. A review on the human health impact of airborne particulate matter. Environ Int 2015; 74: $136-143$.

3 Stone V, Miller MR, Clift MJD, et al. Nanomaterials versus ambient ultrafine particles: an opportunity to exchange toxicology knowledge. Environ Health Perspect 2017; 125: 106002.

4 Cassee FR, Morawska L, Peters A. White Paper Ambient ultrafine particles: evidence for policy makers. Thinking outside the box team. www.efca.net/files/WHITE\%20PAPER-UFP\%20evidence\%20for\%20policy\%20makers\%20 (25\%20OCT).pdf

5 Peters A, Rückerl R, Cyrys J. Lessons from air pollution epidemiology for studies of engineered nanomaterials. J Occup Environ Med 2011; 53: S8-S13.

6 Li N, Sioutas C, Cho A, et al. Ultrafine particulate pollutants induce oxidative stress and mitochondrial damage. Environ Health Perspect 2003; 111: 455-460.

7 Health Effects Institute. Understanding the Health Effects of Ambient Ultrafine Particles. Health Effects Institute Research Report. 2013. www.healtheffects.org/publication/understanding-health-effects-ambient-ultrafine-particles

8 Ohlwein S, Kappeler R, Joss MK, et al. Health effects of ultrafine particles: a systematic literature review update of epidemiological evidence. Intern J Public Health 2019; 64: 547-559.

9 US EPA. 2019. Integrated Science Assessment (ISA) for Particulate Matter. https://www.epa.gov/isa/integratedscience-assessment-isa-particulate-matter. Date last accessed: 14 September 2020.

10 Moher D, Liberati A, Tetzlaff J, et al. Preferred reporting items for systematic reviews and meta-analyses: the PRISMA statement. PLoS Med 2009; 6: e1000097.

11 Halonen JI, Lanki T, Yli-Tuomi T, et al. Urban air pollution, and asthma and COPD hospital emergency room visits. Thorax 2008; 63: 635-641.

12 Belleudi V, Faustini A, Stafoggia M, et al. Impact of fine and ultrafine particles on emergency hospital admissions for cardiac and respiratory diseases. Epidemiology 2010; 21: 414-423.

13 Braniš $\mathrm{M}$, Vyškovská J, Malý $\mathrm{M}$, et al. Association of size-resolved number concentrations of particulate matter with cardiovascular and respiratory hospital admissions and mortality in Prague, Czech Republic. Inhal Toxicol 2010; 22: Suppl. 2, 21-28.

14 Andersen ZJ, Wahlin P, Raaschou-Nielsen O, et al. Size distribution and total number concentration of ultrafine and accumulation mode particles and hospital admissions in children and the elderly in Copenhagen, Denmark. Occup Environ Med 2008; 65: 458-466.

15 Iskandar A, Andersen ZJ, Bønnelykke K, et al. Coarse and fine particles but not ultrafine particles in urban air trigger hospital admission for asthma in children. Thorax 2012; 67: 252-257.

16 Veroniki AA, Jackson D, Viechtbauer W, et al. Methods to estimate the between-study variance and its uncertainty in meta-analysis. Res Synth Methods 2016; 7: 55-79.

17 Samoli E, Atkinson RW, Analitis A, et al. Differential health effects of short-term exposure to source-specific particles in London, UK. Environ Int 2016; 97: 246-253.

18 Samoli E, Andersen ZJ, Katsouyanni K, et al. Exposure to ultrafine particles and respiratory hospitalisations in five European cities. Eur Respir J 2016; 48: 674-682.

19 Morawska L, Ristovski ZD, Jayaratne ER, et al. Ambient nano and ultrafine particles from motor vehicle emissions: characteristics, ambient processing and implications on human exposure. Atmos Environ 2008; 42: 8113-8138.

20 Leitte AM, Schlink U, Herbarth $\mathrm{O}$, et al. Size-segregated particle number concentrations and respiratory emergency room visits in Beijing, China. Environ Health Perspect 2011; 119: 508-513.

21 Sinclair AH, Tolsma D. Associations and lags between air pollution and acute respiratory visits in an ambulatory care setting: 25-month results from the aerosol research and inhalation epidemiological study. J Air Waste Manag Assoc 2004; 54: 1212-1218.

22 Peel JL, Tolbert PE, Klein M, et al. Ambient air pollution and respiratory emergency department visits. Epidemiology 2005; 16: 164-174.

23 Evans KA, Halterman JS, Hopke PK, et al. Increased ultrafine particles and carbon monoxide concentrations are associated with asthma exacerbation among urban children. Environ Res 2014; 129: 11-19. 
24 Díaz-Robles LA, Fu JS, Vergara-Fernández A, et al. Health risks caused by short term exposure to ultrafine particles generated by residential wood combustion: a case study of Temuco, Chile. Environ Int 2014; 66: 174-181.

25 Atkinson RW, Fuller GW, Anderson HR, et al. Urban ambient particle metrics and health: a time-series analysis. Epidemiology 2010; 21: 501-511.

26 Lanzinger S, Schneider A, Breitner S, et al. Ultrafine and fine particles and hospital admissions in Central Europe. Results from the UFIREG study. Am J Respir Crit Care Med 2016; 194: 1233-1241.

$27 \mathrm{Li} \mathrm{Q}, \mathrm{Yi} \mathrm{Q}$, Tang L, et al. Influence of ultrafine particles exposure on asthma exacerbation in children: a meta-analysis. Curr Drug Targets 2019; 20: 412-420.

28 Götschi T, Heinrich J, Sunyer J, et al. Long-term effects of ambient air pollution on lung function: a review. Epidemiology 2008; 19: 690-701.

29 García-Hernández C, Ferrero A, Estarlich M, et al. Exposure to ultrafine particles in children until 18 years of age: a systematic review. Indoor Air 2020; 30: 7-23.

30 Cyrys J, Pitz M, Heinrich J, et al. Spatial and temporal variation of particle number concentration in Augsburg, Germany. Sci Total Environ 2008; 401: 168-175.

31 Clifford S, Mazaheri M, Salimi F, et al. Effects of exposure to ambient ultrafine particles on respiratory health and systemic inflammation in children. Environ Int 2018; 114: 167-180. 